\title{
Imagining Intergroup Contact Can Improve Intergroup Attitudes
}

\author{
Rhiannon N. Turner \\ University of Leeds \\ Richard J. Crisp \\ University of Kent \\ Emily Lambert \\ University of Birmingham
}

\begin{abstract}
We investigated whether simply imagining contact with outgroup members can improve intergroup attitudes. In Experiment 1, young participants who imagined talking to an elderly person subsequently showed lower levels of intergroup bias than participants who imagined an outdoor scene. In Experiment 2, young participants who imagined talking to an elderly person subsequently showed lower levels of intergroup bias than participants who simply thought about elderly people, ruling out a priming explanation for our findings. In Experiment 3, heterosexual men who imagined talking to a homosexual man subsequently evaluated homosexual men more positively, perceived there to be greater variability among them, and experienced less intergroup anxiety compared to a control group. The effect of imagined contact on outgroup evaluations was mediated by reduced intergroup anxiety. These findings suggest that imagining intergroup contact could represent a viable alternative for reducing prejudice where actual contact between groups is impractical.
\end{abstract}

KEYWORDS intergroup contact, reducing prejudice

IN 1954, Gordon Allport proposed that contact between members of opposing groups, under the right conditions, would lessen intergroup hostility and lead to more positive intergroup attitudes (Allport, 1954). Subsequent research has supported this premise but to date this research has usually involved either actual contact or retrospective reports of past actual contact. In this article we ask whether actual contact with outgroups is a necessary component in interventions derived from the contact hypothesis, or whether simply imagining contact with outgroups may be enough to have a positive impact on intergroup relations.

\section{Intergroup contact}

According to Allport (1954) simple contact between groups would not be sufficient to improve intergroup relations. Rather, for contact between groups to reduce prejudice, certain prerequisite conditions must be in place. Specifically, Allport proposed that optimal intergroup contact would

\section{$\overline{\text { Author's note }}$}

Address correspondence to Rhiannon Turner at the Institute of Psychological Sciences, University of Leeds, Leeds LS2 9JT, UK [email: r.n.turner@leeds.ac.uk] 
be of equal status, involve cooperation to achieve common goals, and should be supported by important societal institutions. Over the past 50 years, a great deal of research has been devoted to testing and amending the basic principles of the contact hypothesis and contact is now one of the most widely used psychological interventions for the reduction of prejudice and the improvement of intergroup relations (Oskamp \& Jones, 2000).

The theory has had to deal with various controversies over the years. Past debate has focused on whether the proposed optimal conditions are sufficient, or even necessary, for contact to reduce prejudice, and whether the positive effects of successful intergroup contact would generalize from the individuals involved in the contact to the entire outgroup. However, a recent meta-analysis of over 500 studies on intergroup contact conducted by Pettigrew and Tropp (2006) found a robust highly significant negative effect of contact on prejudice, an effect that remained even for contact that did not meet the proposed 'optimal conditions', and for generalized measures of outgroup prejudice.

Having confirmed that contact does indeed result in more positive generalized outgroup attitudes, even under less than optimal conditions, recent research has concerned itself with how contact reduces prejudice-that is, the processes that underlie the effect of contact-and what consequences contact has for intergroup relations. Below we expand on these two developments. First, we discuss intergroup anxiety, a negative emotional arousal that can characterize intergroup encounters, the reduction of which is thought to be a key process underlying the effect of intergroup contact. Second, we outline research which shows that contact has both cognitive and affective consequences.

\section{Intergroup anxiety}

Stephan and Stephan (1985) argued that intergroup anxiety can arise as a consequence of negative expectations of rejection or discrimination during cross-group interactions, or fears that the interaction partner, or the respondents themselves, may behave in an incompetent or offensive manner. These fears may lead people to avoid intergroup contact altogether. Plant and Devine (2003), for example, found that the more negative White people's expectations about interacting with Black people were, the more they reported avoiding encounters with Black people. Similarly, Shelton and Richeson (2005) found that participants explained their failure to initiate intergroup contact in terms of their fear of being rejected by outgroup members because they belonged to a different group. Even if contact does arise, intergroup anxiety increases the likelihood that individuals will enter the encounter with feelings of hostility (Plant \& Devine, 2003). In turn, this increases the likelihood that group members will interpret the interaction in a negative light, with negative consequences for intergroup relations.

Intergroup anxiety is likely to arise where there has been minimal previous contact and when there are large differences in status (Stephan \& Stephan, 1985). When individuals have had a successful interaction with an outgroup member, however, their level of intergroup anxiety is likely to be reduced, as they come to realize they have nothing to fear from the outgroup. Consistent with this reasoning, a number of studies, in diverse intergroup settings, have found the effect of intergroup contact on reducing prejudice to be mediated by intergroup anxiety (Islam \& Hewstone, 1993; Paolini, Hewstone, Cairns, \& Voci, 2004; Voci \& Hewstone, 2003).

\section{Affective and cognitive consequences of contact}

Affective components of prejudice reflect feelings and emotional responses to a group, for example liking of an outgroup, whereas cognitive components of prejudice are generally considered to relate to perceptions, judgments and stereotypes about a group. Research has demonstrated that intergroup contact can reduce both affective and cognitive forms of prejudice, although typically intergroup contact has a more powerful effect on affective than cognitive outcome measures (Tropp \& Pettigrew, 2005; Wolsko, Park, Judd, \& Bachelor, 2003). 
With respect to cognitive outgroup measures, studies have shown that in addition to generating more positive attitudes (outgroup members are better liked), intergroup contact leads to greater perceptions of outgroup variability.

People have a general tendency to show an 'outgroup homogeneity effect' (Quattrone \& Jones, 1980). That is, we have a general tendency to assume that outgroup members are relatively more homogeneous than ingroup members. This is largely because we encounter few outgroup members and therefore have little knowledge of the diversity among them and because, initially at least, interactions with the outgroup tend to be superficial, constrained by social norms, and lacking in intimacy. Seeing outgroup members as relatively homogeneous may initially help the positive effects of contact to generalize from the individual involved in the contact to the outgroup as a whole (Hewstone \& Hamberger, 2000). Successful intergroup contact should, however, subsequently lead to an increase in perceptions of outgroup variability, as we learn more about the unique characteristics of the outgroup members we meet. This is beneficial for intergroup relations as it increases the amount of information searched for when developing impressions of individual outgroup members (Ryan, Bogart, \& Vender, 2000), decreases the confidence in judging them solely on the basis of group-based stereotypes (Ryan, Judd \& Park, 1996), and reduces the memory advantage for stereotype-congruent information (Pendry \& Macrae, 1999).

A number of studies have demonstrated the effect of contact on outgroup attitudes and perceived outgroup variability. Islam and Hewstone (1993) found, in the context of Muslim-Hindu relations in Bangladesh, that the more high quality contact (contact of a pleasant, intimate, cooperative, and voluntary nature) that participants had experienced, the more positive their outgroup attitudes were and the greater their perceptions of outgroup variability. Similarly, Voci and Hewstone (2003; Study 1) found that contact was related to more positive attitudes and increased perceived outgroup variability among Italians toward immigrants, while Paolini et al. (2004) found that cross-group friendship, a uniquely high quality form of intergroup contact, led to more positive attitudes and increased perceived outgroup variability among Catholics and Protestants in Northern Ireland. In sum, recent developments in research on contact reveal that the effect of intergroup contact is mediated by intergroup anxiety, and that intergroup contact can reduce both affective and cognitive forms of prejudice.

Despite the clear benefits of intergroup contact, however, it has one inevitable limitation; it can only be used as an intervention to reduce prejudice when group members have the opportunity for contact in the first place (e.g. Phinney, Ferguson, \& Tate, 1997; Turner, Hewstone, \& Voci, in press). Unfortunately, there are many examples of opposing groups that have few such opportunities; many Catholic and Protestant communities in Belfast have a very low percentage of residents from the opposing community, and only $5 \%$ of Northern Irish children attend mixed Catholic-Protestant schools (Census, 2001). Similarly, despite being a very multicultural city, many South Asian and White communities in the British city of Bradford remain largely isolated from one another. In such circumstances, interventions that involve intergroup contact may be very difficult to establish. Yet it is in these types of context where contact-based interventions to reduce prejudice are needed the most. One solution to this dilemma is to utilize intergroup contact in an indirect manner. To date, research on the indirect application of intergroup contact has focused on extended contact.

\section{Extended contact}

One of the most significant recent advances in contact research is the finding that perceivers need not have actually experienced contact with the outgroup themselves to develop more positive intergroup attitudes. Specifically, Wright, Aron, McLaughlin-Volpe, and Ropp (1997) provide evidence that so-called extended contact can reduce intergroup bias. The idea behind extended contact is that the benefits associated with cross-group friendship might also stem from vicarious experiences of friendship-the 
knowledge that ingroup members have friends in the outgroup. If an outgroup member is observed being friendly and positive to ingroup members, expectations about intergroup interactions may be more positive, while seeing an ingroup member showing tolerance toward the outgroup may have a positive influence on the attitudes of other ingroup members. Extended contact may be especially useful in situations where there is less opportunity for contact, as it implies that an individual may not need to know personally an outgroup member in order to benefit from the positive effects of cross-group friendship. Subsequent research among Finnish teenagers (Liebkind \& McAlister, 1999) and among Catholics and Protestants in Northern Ireland (Paolini et al., 2004) has also supported the idea that extended contact can benefit intergroup relations.

The implication from work on extended contact is that actual experience of contact with outgroups is not a necessary component of contact interventions. The importance of this idea for policy makers and educators seeking to develop interventions designed to reduce intergroup bias cannot be understated because it suggests that contact may be a far more powerful and flexible means of improving intergroup relations than previously thought. In fact, one may ask whether it is even necessary to know ingroup members who have friends in the outgroup in order for contact to exert a positive effect. Perhaps, simply imagining contact between oneself and an outgroup member is sufficient to observe more positive outgroup attitudes. Some recent work on the impact of mental imagery on social perception adds some credence to this basic idea.

\section{Imagined intergroup contact}

Social psychological research often involves demonstrating the effects of social context on attitudes and behavior. Recently, however, research has shown that simply imagining a particular social context can have the same effect as actually experiencing that context. Garcia, Weaver, Moskowitz, and Darley (2002) investigated the role of imagining a social context on the bystander apathy effect, the idea that people are less likely to help others if there are other people present who might offer help instead. They found that just imagining being in a large group led to significantly less helping behavior on a subsequent task: participants who imagined having a meal out with ten other people were subsequently less likely to help the experimenter by participating in a second study than those who imagined having a meal out with just one other person. Blair, Ma, and Lenton (2001) found imagery to have a similar effect on person perception. Participants who were asked to spend a few minutes creating a mental image of a strong woman showed less implicit gender stereotyping than participants who had created a mental image of a vacation in the Caribbean.

The effect of imagining a social context on subsequent attitudes and behavior may be explained in terms of priming effects. There is considerable evidence that the subtle cues or 'primes' in our social environment activate associated knowledge structures in our minds. As these knowledge structures become more accessible in memory, they often have a powerful influence on our attitudes and behaviors. Bargh, Chen, and Burrows (1996), for example, found that getting White participants to think about African Americans led them to behave in a more hostile manner (where hostile was a perceived stereotypic trait of African Americans). According to Garcia et al. (2002), activating a social context has a similar effect to activating a stereotype; it increases the accessibility of abstract concepts associated with that social context. Imagining being in a crowd, for example, activates feelings of being 'lost in a crowd' and 'unaccountable', feelings which are associated with less helping behavior in real situations.

Following from this logic, imagining intergroup contact should activate concepts that we normally associate with successful interactions with members of unknown groups, such as feeling more comfortable and less apprehensive about the prospect of future contact with that group. In addition to these relatively automatic 
activations, when people imagine intergroup contact they should also engage in conscious processes that parallel the processes involved in actual intergroup contact. They may, for example, actively think about what they would learn about the outgroup member, how they would feel during the interaction, and how this would influence their perceptions of that outgroup member and the outgroup more generally. In turn, this should lead to more positive evaluations of the outgroup, similar to the effects of face-to-face contact (e.g. Islam \& Hewstone, 1993; Paolini et al., 2004; Voci \& Hewstone, 2003).

There is an important theoretical issue to highlight here. The findings of Bargh et al. (1996) illustrate that getting participants to think about an outgroup category often generates negative intergroup attitudes and behavior. So why should we expect imagining intergroup contact with an outgroup member to generate positive intergroup attitudes and behaviors? Undoubtedly, when imagining intergroup contact thoughts of the social category will be present; without it, one would not expect to observe any generalized attitudes to the outgroup category and reduced intergroup bias. However, imagining contact does not simply involve social category priming. While Bargh and colleagues got people to think about a negatively perceived social category, imagining intergroup contact involves participants imagining themselves in a particular social situation; an intergroup encounter. Thus, participants will not only be thinking about the outgroup category but also the interaction itself. Participants might, for example, think about the topic of conversation, how they would behave toward the interaction partner, and how that individual would behave in return. As such, we would not expect a simple priming of negative attitudes, but quite the opposite, consistent with the effects of actual contact.

In the research reported below we investigated the effect of imagined contact in two different intergroup contexts: young people's attitudes toward the elderly in Experiments 1 and 2, and straight men's attitudes toward gay men in Experiment 3, using two different versions of our imagined contact task.

\section{Experiment 1}

In Experiment 1, we carried out an initial test of the hypothesis that imagining intergroup contact would reduce intergroup bias. Young participants were either instructed to imagine interacting with an elderly person or, in a control condition, to imagine an outdoor scene. If imagining contact can have similar effects as actual intergroup contact, imagining contact with an elderly person should result in reduced intergroup bias compared to the control condition.

\section{Method}

Participants Twenty-eight undergraduate students, 23 male and 5 female, aged between 18 and 20, were randomly allocated to either the imagined contact condition or a control condition. Participants received course credit for taking part in the research.

Procedure Prior to the start of the experiment, the researcher told the participant that they were running a pre-test for a possible later experiment and needed to gain some information for the construction of materials. We created two sets of instructions, designed to either invoke participants' imagination of a detailed interaction with an outgroup member, or their imagination of something totally unrelated to a contact encounter. Participants assigned to the imagined contact condition were asked: 'We would like you to take a minute to imagine yourself meeting an elderly stranger for the first time. Imagine their appearance, the conversation that follows and, from what you learn, all the different ways you could classify them into different groups of people'. Participants assigned to the control condition were asked: 'We would like you to take a minute to imagine an outdoor scene. Try to imagine aspects of the scene about you (e.g. is it a beach, a forest, are there trees, hills, what's on the horizon)'. In both conditions, participants were given exactly one minute to imagine the scene. Participants in the imagined contact condition were then instructed to 'List the different ways in which you could classify the stranger following the conversation you just 
imagined', whereas participants in the control condition were instructed to simply 'List the different things that you saw in the scene you just imagined'. This was designed to reinforce the effect of the imagery task.

Following this manipulation, participants completed a measure to assess their level of intergroup bias. They were told:

We may be carrying out a study shortly in conjunction with a local old people's home where we will get either young people to converse with other young people, elderly people to converse with other elderly people, or young people to converse with elderly people. We are gauging whether people would be willing to take part in such a "conversation" study (it would be carried out in the School of Psychology, would last 20 minutes, and you would receive $£ 5$ ). If you were to sign-up for this study, can you rate your preference for the pairing you would be most happy being put in to.

Participants were asked to circle their preference for working with another young person ('Young-Young' pairing) and then their preference for working with an elderly person ('Young-Elderly' pairing) on a 9-point scale $(1=$ not at all, $9=$ very $m u c h)$. An 'Elderly-Elderly' pairing rating scale was also included to reinforce the impression that elderly people were also being asked the same questions in preparation for this supposed future study; our participants were instructed to ignore this question. After completing the dependent measure, participants were asked what they thought the aim of the study was, and whether they were at all suspicious that the pre-test was looking at anything other than what was stated. After providing demographic information, participants were then thanked and debriefed.

\section{Results}

To determine whether imagining intergroup contact with an elderly person reduced intergroup bias compared to a control condition in which participants simply imagined an outdoor scene, we conducted a 2 (Task: Control versus Imagined Contact) $\times 2$ (Target of evaluation: Ingroup versus Outgroup) mixed design analysis of variance (ANOVA), with repeated measures on the second factor. The degree of intergroup bias was therefore determined by calculating the difference in the extent to which participants are willing to interact with an ingroup member and an outgroup member. The analyses revealed the predicted significant interaction between task and target $(F(1,26)=4.50, p=.044$; see Table 1). Planned $t$ tests revealed that while there was significant intergroup bias in the control condition $\left(M_{\text {ingroup }}=7.50, M_{\text {outgroup }}=6.36\right.$; $t(13)=2.58, p=.023)$, there was no significant difference between ingroup and outgroup evaluations in the imagined contact condition $\left(M_{\text {ingroup }}=5.71, M_{\text {outgroup }}=6.71 ; t(13)=-1.10\right.$, $p=.291)$.

Table 1. Mean ingroup and outgroup preference and bias as a function of task in Experiment 1 (standard deviations in parentheses)

\begin{tabular}{lcr}
\hline & \multicolumn{2}{c}{ Task } \\
\cline { 2 - 3 } & Control & $\begin{array}{c}\text { Imagined } \\
\text { contact }\end{array}$ \\
\hline Ingroup preference & $7.50(1.16)$ & $5.71(2.30)$ \\
Outgroup preference & $6.36(1.28)$ & $6.71(1.54)$ \\
Intergroup bias & $1.14(1.66)$ & $-1.00(3.40)$ \\
\hline
\end{tabular}

This experiment provided some initial evidence that simply imagining contact with an outgroup member can reduce intergroup bias. It is worth noting that the reduction in intergroup bias in the imagination condition was driven primarily by a decrease in preference for interacting with an ingroup member. This is not, however, surprising given that the imagined contact task in Experiment 1 involved making multiple categorizations. In contrast to the recategorization of members of two groups into a new inclusive group, which reduces intergroup bias because it leads to a more positive outgroup evaluation, encouraging people to categorize others along multiple dimensions has been shown to reduce intergroup bias by leading to a less positive ingroup evaluation (Crisp, Hewstone, \& Rubin, 2001).

One potential criticism of these findings is that participants may have been influenced by demand characteristics; that is, participants may have responded more positively in the imagined 
contact condition because they guessed the rationale of the experiment and behaved in accordance with the perceived expectations of the experimenter. However, feedback following the experiment revealed that none of the participants were suspicious about its purpose, nor did any of them successfully guess the purpose of the experiment. We can therefore rule out a demand characteristics explanation for our findings.

A second potential criticism of Experiment 1 is that perhaps imagined contact did not involve imagining contact at all, but instead simple category priming. As we noted in the introduction, priming would typically be expected to elicit negative attitudes and behaviors (e.g. Bargh et al., 1996), which is the opposite of what we observed in Experiment 1. However, given the use of explicit measures, perhaps imagined contact simply primed participants to think of the outgroup (the elderly), which then led to a conscious attempt to regulate behavior to appear non-prejudiced (e.g. Devine \& Monteith, 1999). Although on the basis of the feedback received from participants we are confident that a priming/self-regulation effect cannot account for the findings, to empirically rule out this explanation we carried out a second experiment in which we sought to replicate the effects observed in Experiment 1 but using a control condition in which we primed the outgroup.

\section{Experiment 2}

To compare the effect of social category priming and imagined contact, in Experiment 2 young participants were instructed to either imagine interacting with an elderly stranger or to simply think about the elderly. If, as we predict, imagined contact does not simply involve category priming and associated selfregulation, but that there is something special about mentally simulating the intergroup interaction, participants in the imagined contact condition should show lower intergroup bias than participants in the social category prime condition. If imagining intergroup contact simply involves priming and self-regulation, then there should be no difference between bias observed in the prime and imagined contact conditions; in both conditions there should be no significant levels of bias.

\section{Method}

Participants Twenty-four undergraduate students, 12 female and 12 male, aged between 19 and 26 , were randomly allocated to either the imagined contact condition or a control condition, in which participants were simply primed to think about the outgroup. Participants received money or course credit for taking part in the research.

Procedure The procedure was the same as Experiment 1, with one key difference. Instead of imagining an outdoor scene, participants in the control condition were told 'We would like you to spend a minute thinking about the elderly'.

\section{Results}

To determine whether imagining intergroup contact with an elderly person reduced intergroup bias compared to a control condition in which participants were simply primed with the social category elderly, we computed a 2 (Task: Prime versus Imagined Contact) $\times 2$ (Target of evaluation: Ingroup versus Outgroup) mixed design ANOVA, with repeated measures on the second factor. The degree of intergroup bias was therefore determined by calculating the difference in the extent to which participants were willing to interact with an ingroup member compared to an outgroup member. The analyses revealed the predicted significant interaction between task and target $(F(1,21)=5.09$, $p=.035$; see Figure 1). Planned $t$ tests revealed that while there was significant intergroup bias in the control prime condition $\left(M_{\text {ingroup }}=6.73\right.$, $\left.M_{\text {outgroup }}=4.91 ; t(10)=2.29, p=.045\right)$, there was no significant difference between ingroup and outgroup evaluations in the imagined contact condition $\left(M_{\text {ingroup }}=5.75, M_{\text {outgroup }}=5.92\right.$; $t(11)=-.394, p=.701)$. These findings confirm our prediction that while imagining intergroup contact with the elderly reduces intergroup bias, simply thinking about the elderly-in other words, priming the social category-does not. 


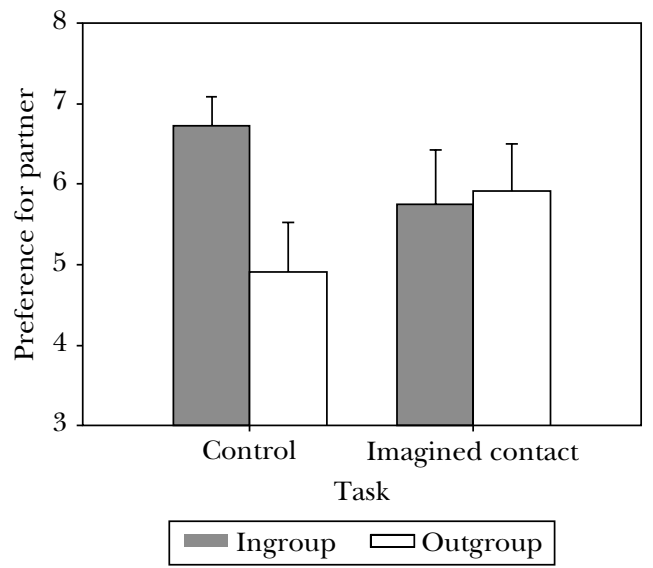

Figure 1. Mean ingroup and outgroup preference as a function of task in Experiment 2.

In contrast to what we would expect if priming a social category led to a self-regulation process in this context, there was significant bias when participants just thought about the elderly, but not when participants imagined intergroup contact. In sum, imagining intergroup contact does not simply involve priming an outgroup category.

As in Experiment 1, feedback following the experiment revealed that while three participants voiced suspicions about the aims of the experiment, none successfully guessed its rationale. This again enables us to rule out a demand characteristics explanation for our findings.

In Experiment 3 we sought to extend and replicate the imagined contact effect with an alternative intergroup dichotomy and with alternative measures of intergroup attitudes. We made two additional changes to the experiment. First, we slightly altered the imagined contact task. As we note above, the task in Experiments 1 and 2 involved an element of multiple categorization. To determine that it was imagining the intergroup contact, rather than just the multiple categorization element of the task, that reduced intergroup bias, in the third experiment we eliminated this multiple categorization element. Instead, we asked participants to think about the interesting and unexpected things they might learn about the outgroup member during the imagined encounter.

Second, we aimed to uncover the mediating mechanisms that may drive the effect of imagined contact. Wright et al. (1997) found that extended contact works via reduced intergroup anxiety, supporting the idea that anxiety reduction is key to the positive impact contact has on intergroup attitudes, and suggesting that actual contact is not necessary to observe reductions in bias via this mediational route. Having demonstrated in Experiments 1 and 2 that imagining contact with outgroups can reduce intergroup bias, in Experiment 3 we aimed to test whether the positive impact of imagining contact with outgroups works via reduced anxiety.

\section{Experiment 3}

In Experiments 1 and 2, we showed that simply imagining contact with the elderly reduces intergroup bias. In Experiment 3 we aimed to replicate this effect with a different outgroup, homosexual males. Heterosexual male participants were instructed either to imagine interacting with a homosexual male, or to imagine a hiking trip. Previous research on intergroup contact has shown it to affect cognitive and affective indices of prejudice, for example perceived outgroup variability and outgroup attitude (Islam \& Hewstone, 1993; Paolini et al., 2004) so we included both types of measure here. Contact has also been shown to reduce prejudice because it reduces intergroup anxiety (Islam \& Hewstone, 1993; Voci \& Hewstone, 2003). If, as we predict, imagined contact works in much the same way as direct intergroup contact, it should also work via the mediating mechanism of intergroup anxiety.

\section{Method}

Participants Twenty-seven male heterosexual undergraduate students, aged between 19 and 25 , were randomly allocated to either the imagined contact condition or a control condition. Participants received course credit for their involvement. 
Procedure The procedure was the same as in Experiments 1 and 2 apart from the following minor improvements that we believed more accurately captured the experience of intergroup contact. Participants assigned to the imagined contact condition were asked:

Please spend the next five minutes imagining that you are talking to a gay man that has sat next to you on the train. You spend about thirty minutes chatting until you reach your stop and depart the train. During the conversation you find out some interesting and unexpected things about him,

before being instructed to think about what those things were and list them. Participants assigned to the control condition were asked: 'Please spend the next five minutes imagining that you are on a three day hiking trip in the south of England. During the trip you arrive unexpectedly at a secluded bay'. They were then asked to imagine and list the different things that they saw at the scene.

Following this manipulation, participants completed the dependent measures. To assess intergroup anxiety, participants were asked: 'If you were to meet a gay man in the future, how do you think you would feel?' They reported, on a 7-point scale, how 'Awkward', 'Happy' (reversed), 'Self-Conscious', 'Competent' (reversed), and 'Relaxed' (reversed) they would feel ( 1 = not at all, 7 = very; $\alpha=.80$; Voci \& Hewstone, 2003). To measure outgroup evaluation, participants were first asked to 'Please describe how you feel about gay men in general', responding to six items (from Voci \& Hewstone, 2003) on 7-point semantic differential scales: cold-warm, positivenegative (reversed), friendly-hostile (reversed), suspicious-trusting, respectful-contempt (reversed), admiration-disgust (reversed). We also included a three-item scale of attitudes toward gay men (Herek \& Capitanio, 1996). Participants were asked to rate how much they agreed or disagreed, on a 7 -point scale $(1=$ disagree, $7=$ agree $)$, with the following statements: 'Sex between two men is just plain wrong' (reversed), 'I think male homosexuals are disgusting' (reversed), and 'Male homosexuality is a natural expression of sexuality in men'. As the two sets of outgroup evaluation items loaded on the same factor, they were combined to form a composite variable $(\alpha=.86)$. Finally, perceived outgroup variability was assessed using three items averaged to form a single index $\left(\alpha=.55^{1}\right)$ : 'When you think about gay men, do you perceive them as similar to one another?', 'When you think about gay men, do you perceive them as different to one another?' (both items, $1=$ not at all, $7=$ very), and 'Among gay men there are different types of people $(1=$ disagree, $7=$ agree ; first item reverse coded). High scores reflected greater perceived outgroup variability.

After completing the dependent measure, participants were asked what they thought the aim of the experiment was, and whether they were at all suspicious that it was looking at anything other than what was stated. After providing demographic information, participants were then thanked and debriefed.

\section{Results}

To determine whether imagining intergroup contact with a gay man led to less intergroup anxiety, more positive outgroup evaluations and greater perceived outgroup variability compared to a control condition we computed planned $t$ tests. This analysis revealed significantly less intergroup anxiety following the imagined contact task $(M=2.97)$ compared to the control condition $(M=4.05) ; t(25)=-3.71, p=.001)$; significantly more positive outgroup evaluations following the imagined contact task $(M=3.82)$ compared to the control condition $(M=3.02)$ $(t(25)=2.10, p=.046)$; and significantly greater perceived outgroup variability following the imagined contact task $(M=4.64)$ compared to the control condition $(M=3.97)(t(25)=-2.18$, $p=.040)$.

We then computed a mediational analysis to assess whether the effect of imagined contact on both outcome measures was mediated by variation in intergroup anxiety. There was a significant path between task and both outgroup evaluation $(\beta=.388, p=.046)$, and outgroup variability $(\beta=.398, p=.040)$. Task also predicted the mediator, anxiety $(\beta=-.596, p=.001)$. The path between anxiety and outgroup variability while controlling for the predictor was not significant $(\beta=-.050, p=.831)$. The path between anxiety and outgroup evaluation while controlling for 
the predictor was, however, significant $(\beta=-.641$, $p=.003)$, and when the mediator was controlled the relationship between task and evaluation became nonsignificant $(\beta=.006, p=.975)$. A Sobel test was significant $(Z=2.47, p=.013$; see Figure 2).

In sum, in Experiment 3, in a different intergroup context and using both affective and cognitive measures of bias, we replicated the positive impact of imagined contact that we observed in Experiments 1 and 2. Furthermore, we found that the bias-reducing effects of imagined contact were mediated by reduced intergroup anxiety. As in the first two experiments, we wanted to rule out a demand characteristics explanation for our findings. We found that one participant in the control condition reported being suspicious that the research was looking at something other than what was stated, but they did not successfully identify what the experiment was actually about. In fact, none of the participants were able to identify what the experiment was about. Given that participants were not aware of the hypothesis, the current findings cannot be explained by demand characteristics.

\section{General discussion}

Supporting our hypothesis, we found across three experiments that imagined intergroup contact was sufficient to observe improved intergroup attitudes. In Experiment 1, participants were asked to imagine contact with an elderly person, and to then think about all the different ways in which they might be able to categorize that person. While participants in a control condition who imagined an outdoor scene showed a greater preference for interacting with a young person than for interacting with an elderly person, participants who imagined intergroup contact showed reduced intergroup bias. In Experiment 2, we replicated the findings from Experiment 1 with a control prime condition in which participants were simply asked to think about the elderly. While participants in this prime condition showed a significantly greater preference for interacting with a young person than for interacting with an elderly person, participants who imagined intergroup contact showed reduced intergroup bias. These findings rule out the possibility that imagining intergroup contact simply primes an outgroup category and leads to a self-regulation process whereby socially desirably responses are elicited.

Experiment 3 provided further support for the benefits of imagined contact, and investigated mediating processes. Male heterosexual participants were asked to imagine contact with a gay man, and to then think about some of the unexpected things they might learn about that person. Participants who spent a few minutes imagining intergroup contact subsequently had

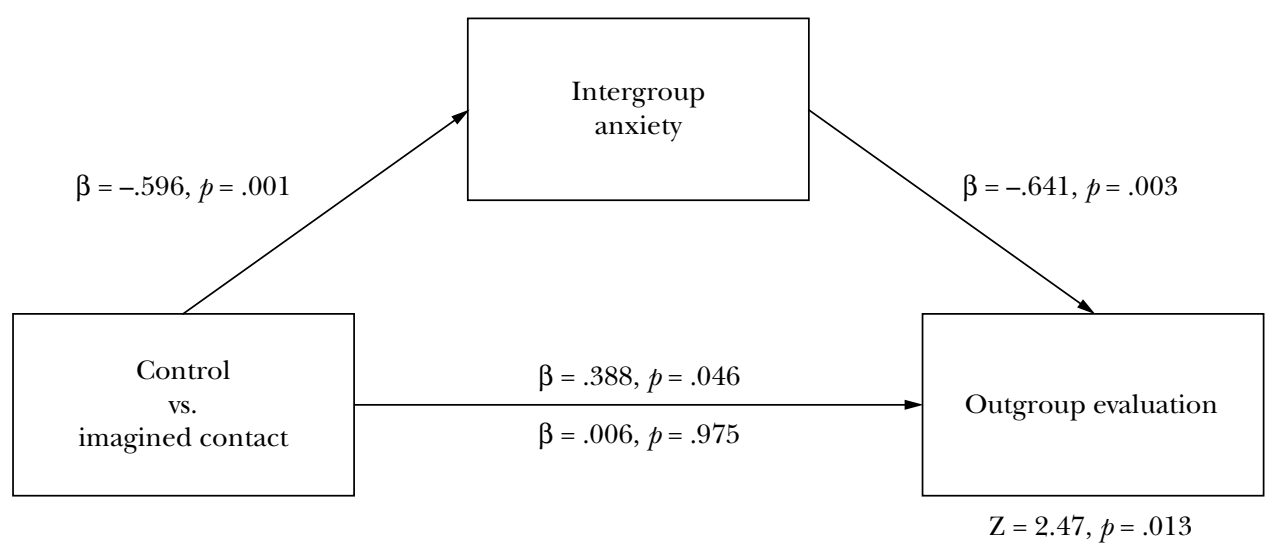

Figure 2. Mediational model of the role of intergroup anxiety in explaining the effects of imagined contact on outgroup evaluation in Experiment 3. 
a more positive attitude toward gay people in general, and also perceived there to be greater variability among the outgroup, than participants in the control condition. That imagined contact worked in two intergroup contexts, using two versions of the imagined contact task, gives us confidence that the effect of imagined contact isn't limited to a specific intergroup context or type of imagined contact.

Experiment 3 also showed that imagined contact has its beneficial effects via that same mediational route as existing work on actual and extended contact; we found that intergroup anxiety explained the positive effects of imagining intergroup contact on outgroup attitudes. While we found that imagining contact with an outgroup member reduced outgroup homogeneity, this was not mediated by anxiety. Although some direct contact studies have found intergroup anxiety to mediate the effect of intergroup contact on outgroup variability (e.g. Islam \& Hewstone, 1993; Voci \& Hewstone, 2003), the evidence for this effect is less consistent than the effect of intergroup anxiety on affective outcome measures, such as feelings of intergroup comfort and liking (e.g. Tropp \& Pettigrew, 2005; Turner et al., in press). Future research is needed to determine when intergroup anxiety will increase perceptions of homogeneity and when it will not have such an effect.

It is worth noting that the participants in the reported studies had relatively positive intergroup attitudes even in the absence of the imagined contact intervention. Thus, although imagining intergroup contact reduced intergroup bias, we cannot conclude on the basis of these findings that imagined contact would be just as effective, say, among Catholics and Protestants in Northern Ireland or Palestinians and Israelis in the Middle East, where intergroup attitudes are sometimes extremely negative. We argue, however, that what is important in the current studies is that in the experimental condition-regardless of the initial level of intergroup bias-participants who imagined intergroup contact showed lower levels of intergroup bias than participants in the control condition who had not imagined such contact. This indicates that imagined contact does have an effect on intergroup bias, but future research is necessary to determine the extent to which imagined contact will be more or less effective in different contexts.

\section{Why does imagined contact work?}

We believe that imagining intergroup contact activates concepts that we normally associate with interactions with members of unknown groups, such as feeling more comfortable and less apprehensive about the prospect of future contact with that group. In addition to these automatic processes, imagining contact is likely to generate conscious processes that parallel the processes involved in actual intergroup contact, for example thinking about what they would learn from the encounter and how that encounter would make them feel. Together, we believe that these processes lead to more positive outgroup attitudes.

One potential criticism of this explanation is that if participants had the opportunity to imagine any contact situation they wanted to, they might have imagined a negative contact situation, particularly if they have a less than positive opinion of the outgroup. So, why did participants who imagined contact, in the absence of any specifically positive instructions, show reduced intergroup bias? The findings of a large-scale meta-analysis of the intergroup contact literature may provide an answer. Pettigrew and Tropp (2006) found that although contact that meets the key conditions proposed by Allport (1954) for high quality contact was particularly effective at reducing prejudice, even 'mere contact', intergroup contact that failed to meet the key conditions proposed by Allport (1954) also frequently led to reductions in prejudice. This may explain why participants who were instructed to imagine intergroup contact in the absence of specific instructions to think of a positive encounter become less biased in their attitudes.

\section{When will imagined contact work?}

Imagining intergroup contact is particularly indirect in nature when compared to actual intergroup contact, involving face-to-face interactions, and even extended contact, which involves knowing ingroup members who have outgroup 
friends. This indirectness gives imagined contact a significant disadvantage on the one hand, but some considerable advantages on the other, over actual and extended intergroup contact. Below, we outline these strengths and weaknesses, and discuss how they help us to identify when imagined contact will be most effective at reducing intergroup bias.

Probably the biggest drawback of imagined contact is that it may not have as powerful or long lasting an effect as more direct forms of intergroup contact. Direct experiences are thought to produce stronger attitudes on an issue than indirect experiences (Fazio, Powell, \& Herr, 1983; Stangor, Sullivan, \& Ford, 1991). Supporting this premise, research comparing direct and extended contact typically shows direct contact to have the stronger impact on prejudice (Paolini et al., 2004; Turner et al., in press). Given that imagined contact is less direct than actual intergroup contact and extended contact, we might expect it to have a weaker and more temporary effect on intergroup bias than either of these interventions.

In comparison with face-to-face contact, however, imagined contact shares two advantages with extended contact. First, imagined contact may be particularly useful in contexts where intergroup conflict and segregation are high and the opportunity for contact is low as, like with extended contact, an individual does not need to know personally an outgroup member. Second, because contact is not experienced first hand, there is less likely to be intergroup anxiety than during direct contact. Moreover, imagining a non-threatening contact situation should encourage people to realize they have no reason to fear members of other groups. Imagined contact also holds a further advantage over both direct and extended contact. Although extended contact can be implemented more widely than direct contact, because an individual only needs to know of an ingroup member who has experienced outgroup contact, imagined contact goes one step further: no experience of outgroup contact, either direct or extended, is necessary to observe improved intergroup attitudes.
In sum, imagined contact may have a less powerful effect than direct or extended contact, but it can be used as an intervention in contexts where direct contact, and even extended contact, cannot be. Moreover, as Experiment 2 illustrated, imagining intergroup contact reduces the fears and negative expectations that often poison face-to-face contact (Plant \& Devine, 2003), and thereby prepares people for a successful intergroup encounter. For this reason, we believe that one way in which imagined contact might be usefully applied is immediately before an intervention that involves direct contact. If participants spend some time imagining intergroup contact before personally engaging in such an encounter, their levels of intergroup anxiety will be lower, their intergroup attitudes more positive, and their expectations greater when they embark on the encounter. This will increase the chance that intergroup contact will result in strong, positive and longlasting attitude change.

\section{Future research}

The current findings present some interesting avenues for future research. First, as we outlined above, there are some intriguing questions surrounding when imagined contact might be most useful. Future research should consider whether the degree of conflict in a particular intergroup context or the negativity of a participant's initial outgroup attitude influences the effectiveness of imagined contact. Furthermore, social psychologists and practitioners might investigate whether interventions involving face-to-face contact are more effective if participants first imagine an intergroup encounter.

A second potential line of research involves ruling out the role of demand characteristics in imagined contact; that is, the possibility that participants completing the imagined contact task may have guessed the rationale of the experiment and subsequently attempted to confirm the experimenter's hypothesis. We do not believe that demand characteristics influenced our results; we did not reveal to participants the nature of the experiment until 
debriefing, and accordingly found that across the three experiments not one participant successfully identified the aims of the experiment. Clearly, if participants did not know what the experiment was about, they cannot have been influenced by demand characteristics. To conclusively rule out this alternative explanation of our findings, however, future research should consider the effects of imagined contact on an implicit measure of intergroup bias, on which participants are unable to actively control their responses. Recent research has found that face-to-face contact predicts implicit outgroup bias (Aberson, Shoemaker, \& Tomolillo, 2004; Turner et al., in press). If, as we predict, imagined contact parallels the effects of face-to-face con-tact, imagined contact should also reduce implicit bias.

\section{Practical implications}

These findings may prove important for the adaptability of contact interventions by policy makers and educators. Community leaders in areas where there is segregation and intergroup tension recognize that positive intergroup contact might reduce prejudice, but they are often faced with practical difficulties that make such changes difficult. In the context of race relations in British cities, for example, 'White flight' from inner city areas to the suburbs has resulted in ethnic minority 'enclaves' in the inner cities, while White communities dominate the outer suburbs. Such situations cannot easily be remedied as they are often related to economic and social inequalities in wider society. Even in multicultural communities where many different groups live in close proximity to one another, we have a tendency to interact mainly with those similar to the self, especially with regard to age, gender, and race (Graham \& Cohen, 1997). Moreover, when intergroup contact does occur, the anticipation of the encounter for those who have had little prior experience with an outgroup may lead to intergroup anxiety, with potentially negative consequences for intergroup contact (Plant \&
Devine, 1993). Imagined contact, however, is an inexpensive and practical means of reducing intergroup anxiety and prejudice that would be useful even where direct contact is very limited. For this reason, it might form an important component of multicultural teaching in schools and communities. Future research should be concerned with identifying the parameters of the effectiveness of the intervention; specifically, in what circumstances it is most likely to benefit intergroup relations.

In conclusion, across three experiments we found that imagining contact with an outgroup member led to more positive intergroup attitudes. In Experiments 1 and 2, young people who imagined an encounter with an elderly person were less biased than control participants, while in Experiment 3, straight men who imagined contact with a gay man had a more positive evaluation of gay men, mediated by reduced intergroup anxiety, and perceived there to be more variability among gay men than control participants. These findings generate a number of interesting avenues for future research, and leave us optimistic about the potential prejudicereducing benefits of indirect interventions based on intergroup contact.

\section{Note}

1. When we omitted the third item the alpha improved to .74 . We obtained exactly the same effects (all $p<.05$ ) using this two item scale in all the subsequent analyses we report that involved perceived outgroup variability as when using the three item index.

\section{Acknowledgements}

The writing of this paper was part-funded by an Economic and Social Research Council Postdoctoral Fellowship (PTA-026-27-1045) awarded to the first author.

We would like to thank Sarah Beck, Lindsey Cameron, Natalie Hall, Russell Hutter, and Mein-Woei Suen for their help with data collection. 


\section{References}

Aberson, C. L., Shoemaker, C., \& Tomolillo, C. (2004). Implicit bias and contact: The role of interethnic friendships. Journal of Social Psychology, 144, 335-347.

Allport, G. W. (1954). The nature of prejudice. Cambridge, MA: Perseus Books.

Allport, G. W. (1985). The historical background of social psychology. In G. Lindzey \& E. Aronson (Eds.), Handbook of social psychology (Vol. I, 3rd ed., pp. 1-46). New York: Random House.

Bargh, J. A., Chen, M., \& Burrows, L. (1996). The automaticity of social behavior: Direct effects of trait concept and stereotype activation on action. Journal of Personality and Social Psychology, 71, 230-244.

Blair, I. V., Ma, J. E., \& Lenton, A. P. (2001). Imagining stereotypes away: The moderation of implicit stereotypes through mental imagery. Journal of Personality and Social Psychology, $81,828-841$.

Census (2001). National statistics government website: Neighbourhood statistics. Retrieved July 24, 2006, from http://neighbourhood.statistics.gov.uk.

Crisp, R. J., Hewstone, M., \& Rubin, M. (2001). Does multiple categorization reduce intergroup bias? Personality and Social Psychology Bulletin, 27, 76-89.

Devine, P. G., \& Monteith, M. J. (1999). Automaticity and control in stereotyping. In S. Chaiken \& Y. Trope (Eds.), Dual-process theories in social psychology (pp. 339-360). New York: Guilford.

Fazio, R. H., Powell, M. C., \& Herr, P. M. (1983). Toward a process model of the attitude-behavior relation: Accessing one's attitude upon mere observation of the attitude object. Journal of Personality and Social Psychology, 44, 723-735.

Garcia, S. M., Weaver, K., Moskowitz, G. B., \& Darley, J. M. (2002). Crowded minds: The implicit bystander effect. Journal of Personality and Social Psychology, 83, 843-853.

Graham, J. A., \& Cohen, R. (1997). Race and sex as factors in children's sociometric ratings and friendship choices. Social Development, 6, 355-372.

Herek, G. M., \& Capitanio, J. P. (1996). 'Some of my best friends': Intergroup contact, concealable stigma, and heterosexuals' attitudes toward gay men and lesbians. Personality and Social Psychology Bulletin, 22, 412-424.
Hewstone, M., \& Hamberger (2000). Perceived variability and stereotype change. Journal of Experimental Social Psychology, 36, 103-124.

Islam, R. M., \& Hewstone, M. (1993). Dimension of contact as predictors of intergroup anxiety, perceived out-group variability and out-group attitudes: An integrative model. Personality and Social Psychology Bulletin, 19, 700-710.

Liebkind, K., \& McAlister, A. L. (1999). Extended contact through peer modelling to promote tolerance in Finland. European Journal of Social Psychology, 29, 765-780.

Oskamp, S., \& Jones, J. M. (2000). Promising practice in reducing prejudice: A report from the President's Initiative on Race. In S. Oskamp (Ed.), Reducing prejudice and discrimination (pp. 319-334). Mahwah, NJ: Erlbaum.

Paolini, S., Hewstone, M., Cairns, E., \& Voci, A. (2004). Effects of direct and indirect cross-group friendships on judgements of Catholics and Protestants in Northern Ireland: The mediating role of an anxiety-reduction mechanism. Personality and Social Psychology Bulletin, 30, 770-786.

Pendry, L. F., \& Macrae, C. N. (1999). Cognitive load and person memory: The role of perceived group variability. European Journal of Social Psychology, 29, 925-942.

Pettigrew, T. F. (1998). Intergroup contact: Theory, research and new perspectives. Annual Review of Psychology, 49, 65-85.

Pettigrew, T. F., \& Tropp, L. R. (2006). A metaanalytic test of intergroup contact theory. Journal of Personality and Social Psychology, 90, 751-783.

Phinney, J. S., Ferguson, D. L., \& Tate, J. D. (1997). Intergroup attitudes among ethnic minority adolescents: A causal model. Child Development, 68, 955-969.

Plant, E. A., \& Devine, P. G. (2003). The antecedents and implications of interracial anxiety. Personality and Social Psychology Bulletin, 29, 790-801.

Quattrone, G. A., \& Jones, E. F. (1980). The perception of variability within in-groups and out-groups: Implications for the law of small numbers. Journal of Personality and Social Psychology, 38, 141-152.

Ryan, C. S., Bogart, L. M., \& Vender, J. P. (2000). Effects of perceived group variability on the gathering of information about individual group members. Journal of Experimental Social Psychology, 36, 90-101. 
Ryan, C. S., Judd, C. M., \& Park, B. (1996). Effects of racial stereotypes on judgments of individuals: The moderating role of perceived group variability. Journal of Experimental Social Psychology, 32, 71-103.

Shelton, J. N., \& Richeson, J. A. (2005). Intergroup contact and pluralistic ignorance. Journal of Personality and Social Psychology, 88, 91-107.

Stangor, C., Sullivan, L. A., \& Ford, T. E. (1991). Affective and cognitive determinants of prejudice. Social Cognition, 9, 359-380.

Stephan, W. G., \& Stephan, C. W. (1985). Intergroup anxiety. Journal of Social Issues, 41, 157-176.

Tropp, L. R., \& Pettigrew, T. F. (2005). Differential relationships between intergroup contact and affective and cognitive dimensions of prejudice. Personality and Social Psychology Bulletin, 31, 1145-1158.

Turner, R. N., Hewstone, M., \& Voci, A. (in press). Reducing explicit and implicit prejudice via direct and extended contact: The mediating role of self-disclosure and intergroup anxiety. Journal of Personality and Social Psychology.

Voci, A., \& Hewstone, M. (2003). Intergroup contact and prejudice toward immigrants in Italy: The mediational role of anxiety and the moderational role of group salience. Group Processes E Intergroup Relations, 6, 37-54.

Wolsko, C., Park, B., Judd, C. M., \& Bachelor, J. (2003). Intergroup contact: Effects on group evaluations and perceived variability. Group Processes $\mathcal{E}$ Intergroup Relations, 6, 93-110.
Wright, S. C., Aron, A., McLaughlin-Volpe, T., \& Ropp, S. A. (1997). The extended contact effect: Knowledge of cross-group friendships and prejudice. Journal of Personality and Social Psychology, 73, 73-90.

Paper received 14 March 2006; revised version accepted 3 September 2006.

\section{Biographical notes}

RHIANNON N. TURNER is a lecturer in social psychology at the University of Leeds. She did her BSc at Cardiff University, her MSc at the University of Kent, and her D.Phil. at the University of Oxford. Her research interests focus on intergroup relations, specifically on dimensions, mediators and consequences of intergroup contact.

RICHARD J. CRISP is Professor of Psychology in the Centre for the Study of Group Processes at the University of Kent. He did his BA at the University of Oxford and his PhD at Cardiff University. His research interests focus on social categorization, group processes, and intergroup relations.

EMILY LAMBERT was formerly a student at the University of Birmingham from where she was awarded her BSc in Psychology. 